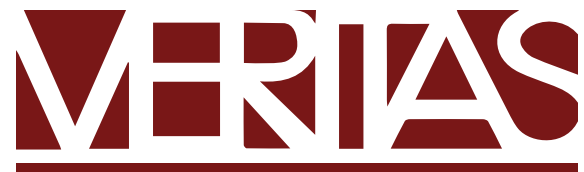

$\begin{array}{lllllllllll}P & O & R & T & O & A & L & E & G & R & E\end{array}$

http://dx.doi.org/10.15448/1984-6746.2019.3.32106

\title{
A COMUNIDADE CIENTÍFICA COMO SUJEITO EPISTÊMICO COLETIVO
}

The scientific community as a collective epistemic subject

La comunidad científica como sujeto epistémico colectivo

Delvair Custódio Moreira'

Universidade Federal do Maranhão, São Luís, MA, Brasil.

\section{Resumo}

Em epistemologia coletiva argumenta-se que grupos podem ser sujeitos epistêmicos. Ou seja, que grupos podem instanciar atitudes doxásticas (como crenças) passíveis de serem avaliadas como racionais, justificadas ou mesmo consideradas casos de conhecimento. Epistemólogos coletivos têm sustentado também que grupos amplos como a comunidade científica podem ser sujeitos epistêmicos. Mas não é óbvio que a comunidade científica seja capaz de formar atitudes doxásticas, mesmo que o argumento que sustente a tese de que grupos têm tais atitudes for sólido. Isto porque a tese de que grupos podem ser sujeitos epistêmicos depende de uma noção

1 Doutor em Filosofia, Universidade Federal de Santa Catarina. Professor na Universidade Federal do Maranhão, MA, Brasil. https://orcid.org/oooo-0002-8732-693X. E-mail: delvair. moreira@ufma.br 
de comprometimento conjunto que a comunidade científica parece não ser capaz de realizar. Seguindo essa linha de raciocínio, objeta-se que a comunidade científica seja capaz de formar atitudes doxásticas. Dada as objeções, a comunidade científica não poderia ser tratada como sujeito epistêmico. Meu objetivo neste trabalho é responder a essas objeções e defender que a comunidade científica pode ser considerada um sujeito epistêmico.

Palavras-chave: Epistemologia coletiva. Sujeito epistêmico coletivo. Conhecimento coletivo. Compromisso conjunto.

\begin{abstract}
In collective epistemology it is argued that groups can be epistemic subjects. That is, groups can instance doxastic attitudes (such as beliefs) that can be evaluated as rational, justified or even cases of knowledge. Collective epistemologists have held that broad groups such as the scientific community as can also be epistemic subjects. But it is not obvious that the scientific community is capable of doxastic attitudes even if the argument supporting the thesis that groups have such attitudes is sound. This, because the thesis that groups can be epistemic subjects depends on a notion of joint commitment that the scientific community seems to be unable to perform. Following this line of reasoning it is objected that the scientific community is not capable of doxastic attitudes. Given these objections the scientific community could not be treated as an epistemic subject. My purpose in this paper is to respond to these objections and to argue that the scientific community can be an epistemic subject.
\end{abstract}

Keywords: Collective epistemology. Collective epistemic subject. Collective knowledge. Joint commitment.

\title{
Resumen
}

En la epistemología colectiva, se argumenta que los grupos pueden ser sujetos epistémicos. Es decir, que los grupos pueden crear actitudes 
doxáticas (como creencias) que pueden ser evaluadas como casos racionales, justificados o incluso considerados de conocimiento. Los epistemólogos colectivos también han sostenido que amplios grupos como la comunidad científica pueden ser sujetos epistémicos. Pero no es obvio que la comunidad científica sea capaz de formar actitudes doxáticas, incluso si el argumento que sustenta la tesis de que los grupos tienen tales actitudes es sólido. Esto se debe a que la tesis de que los grupos pueden ser sujetos epistémicos depende de una noción de compromiso conjunto que la comunidad científica parece no ser capaz de lograr. Siguiendo esta línea de razonamiento, se objeta que la comunidad científica es capaz de formar actitudes doxáticas. Dadas las objeciones, la comunidad científica no podía ser tratada como un tema epistémico. Mi objetivo en este trabajo es responder a estas objeciones y defender que la comunidad científica pueda ser considerada un tema epistémico.

Palabras clave: Epistemología colectiva, asignatura epistémica colectiva, conocimiento colectivo, compromiso conjunto

\section{Introdução}

Neste trabalho eu pretendo defender que a comunidade científica pode ser tratada como um sujeito epistêmico coletivo. Segue-se um breve sumário da discussão a ser desenvolvida: por "sujeito epistêmico" eu quero me referir a uma entidade capaz de atitudes doxásticas passíveis de serem avaliadas como racionais, justificadas ou serem consideradas como casos de conhecimento². Há defesas sólidas na literatura (e.g. GILBERT, 2004;

\footnotetext{
2 Tipicamente a atitude doxástica sujeita a avaliações epistêmicas é a crença. Porém, no presente trabalho, eu pretendo ser neutro à questão de saber se atitudes doxásticas instanciadas por grupos são crenças no mesmo sentido de crenças instanciadas por indivíduos, uma vez que esse ponto é controverso na literatura. Há um amplo debate entre crentes e rejeicionistas: crentes sustentam que as atitudes doxásticas coletivas são crenças genuínas tais como as crenças de indivíduos. Rejeicionistas, por outro lado, sustentam que as atitudes doxásticas de grupos são melhores entendidas como aceitações coletivas. No decorrer do texto, apesar de usar expressões como "crenças coletivas" ou "visões coletivas", com tais expressões quero me referir a atitudes doxásticas em um sentido geral, sem me comprometer com a ideia de que
} 
TUOMELA, 2004) de que grupos podem ser sujeitos epistêmicos, porém essas defesas não parecem plausíveis quando o grupo em questão for maior que uma equipe de pesquisa: alguns epistemólogos têm rejeitado a ideia de que comunidades científicas podem ser sujeitos epistêmicos mesmo que grupos de pesquisa sejam.

K. Brad Wray (2007) argumenta que a comunidade científica não exibe solidariedade orgânica ${ }^{3}$, característica que segundo Wray, é condição necessária para que um grupo seja um sujeito epistêmico. Contra Wray eu pretendo argumentar que o que torna um grupo em um sujeito epistêmico não é a solidariedade orgânica, mas a capacidade de formar um comprometimento conjunto (GILBERT, 1987, 1989, 2004). Porém, uma objeção à minha defesa seria a argumentação de Alexander Bird (2014) que argumenta que a comunidade científica não é capaz de estabelecer um comprometimento conjunto. Por isso, para sustentar minha posição, será necessário argumentar contra Bird que a comunidade científica pode fazer comprometimentos conjuntos.

Este trabalho está organizado da seguinte maneira: na seção 1 eu sumarizo o argumento que demonstra que grupos podem ser sujeitos epistêmicos; na seção 2 eu apresento a defesa de Margaret Gilbert (2000) de que a comunidade científica pode ser tratada como um sujeito epistêmico assim como objeções à posição de Gilbert. Na seção 3, eu apresento as objeções de Wray contra a tese de que a comunidade científica seja um sujeito epistêmico e respondo a essas objeções. Por fim, na seção 4 , eu respondo às objeções de Bird de que a comunidade científica não é capaz de estabelecer um comprometimento conjunto.

\footnotetext{
essas atitudes sejam crenças ou aceitações. Uma exposição do debate entre crentes e rejeicionistas, assim como uma defesa de que é possível ser neutro nessa questão e ainda assim falar de sujeitos epistêmicos coletivos pode ser encontrada em Moreira (2016).

3 Ver seção 3.
} 


\section{Um sumário da defesa de sujeitos epistêmicos coletivos ${ }^{4}$}

$\mathrm{Na}$ linguagem natural é comum atribuições de conhecimento e estados doxásticos (como crenças) a coletividades. Costumamos dizer coisas como "os cientistas sabem que o universo está em expansão" ou "o governo acredita que a inflação está sob controle". Uma vez que em epistemologia o sujeito do conhecimento é tipicamente um indivíduo, as análises de conhecimento costumam ignorar coletividades como sujeitos epistêmicos (TOLLEFSEN, 2002). Não obstante, atribuições de conhecimento e estados doxásticos a grupos podem ser acomodados na epistemologia tratando essas atribuições como formas indiretas de se referir à maioria dos membros que compõem o grupo.

Nessa leitura, expressões como "o grupo G acredita que $p$ " significam que a maioria dos membros de $\mathrm{G}$ acredita que $p$. Em tal visão somatória, como é chamada na literatura, coletividades não são sujeitos epistêmicos uma vez que não possuem estados doxásticos próprios. Porém, a visão somatória sofreu sérios ataques de Margaret Gilbert (1987, 1989, 2004) que colocam em dúvida se a soma das atitudes doxásticas individuais seja uma condição suficiente ou mesmo necessária para a correta atribuição dessas atitudes a coletividades.

O fato de a maioria de uma coletividade acreditar que $p$ não garante que essa coletividade forme um grupo que acredite que $p$, uma vez que crenças nesse sentido existem em meros aglomerados que não consideraríamos grupos. Por exemplo, é plausível que a maioria das pessoas maiores de 18 anos acredite que se colocar a mão no fogo irá se queimar. Mas não parece ser o caso que haja aqui um grupo que acredita que se

\footnotetext{
4 O objetivo nessa seção é, de fato, sumarizar os argumentos utilizados para sustentar a tese de que grupos possam ser sujeitos epistêmicos mais do que oferecer uma defesa exaustiva dessa tese. Isto porque, o ponto principal é saber se da defesa de que grupos sejam sujeitos epistêmicos, segue-se que comunidades também possam ser. Desta forma, tanto a ideia de grupos como agentes coletivos, como a ideia de que grupos possam ser sujeitos epistêmicos são pressupostas para fins de saber se um tipo particular de grupos, a saber, comunidades, também podem ser entendidas como sujeitos epistêmicos coletivos.
} 
colocar a mão no fogo irá se queimar ${ }^{5}$. Além disso, é possível que em um grupo a maioria dos membros não acredite pessoalmente que $p$ enquanto o grupo acredita que $p$. Por exemplo, um Comitê composto por de três professores formado para selecionar um candidato ao novo cargo de professor do Departamento de Filosofia (MATHIESEN, 2011) tem de selecionar o melhor candidato com base em uma série de especificações determinadas pelo departamento. Após seguir os procedimentos, dois dos membros do Comitê pessoalmente não acreditam que Jones seja o melhor candidato. Porém, com base nas especificações do departamento e nas evidências coletivamente aceitas, Jones é considerado o melhor candidato pelo Comitê. O Comitê acredita que Jones é o melhor candidato, apesar de a maioria de seus membros não acreditar pessoalmente nisso. Esse tipo de caso também demonstra que uma crença coletiva é irredutível à soma das crenças individuais dos membros do grupo. Sendo o caráter irredutível dessa crença àquilo que torna possível que grupos sejam sujeitos epistêmicos: uma vez que o grupo exibe uma atitude doxástica que não pode ser reduzida à soma das atitudes instanciadas por seus membros, parece se seguir que é o grupo é quem deve ser tratado como o sujeito dessa atitude.

O que torna possível tais atitudes irredutíveis, segundo Gilbert, é a capacidade do grupo estabelecer um comprometimento conjunto. $\mathrm{Na}$ visão não somatória ou abordagem de sujeito plural de Gilbert, um grupo $\mathrm{G}$ acredita que $p$ quando os membros de $\mathrm{G}$ estabelecem um comprometimento conjunto de acreditar em $p$ como um corpo. As condições para que um comprometimento conjunto de acreditar em $p$ como um corpo se estabeleça, por sua vez, são: as partes envolvidas decidem acreditar em $p$ como um corpo; cada uma das partes expressa publicamente sua

\footnotetext{
5 Um mero aglomerado de pessoas não contaria como um grupo porque grupos têm a capacidade de agir conjuntamente (Cf. SCHMMIT, 2003). Desta forma, o que distingue um grupo de um aglomerado de pessoas é que o primeiro é capaz de ações coletivas. Ações coletivas, por sua vez, "ocorrem se e somente se [...] duas ou mais pessoas fazem alguma coisa juntas" (GILBERT, 2011).
} 
decisão; e há conhecimento comum ${ }^{6}$ entre as partes acerca da decisão de acredita em $p$ como um corpo (MULLER 2012). Acreditar que $p$ como um corpo, por sua vez, significa que os membros do grupo devem fazer sua parte para que seja o caso que o grupo acredite que $p$. Por exemplo, não dizer algo contrário à $p$ enquanto se pronuncia como um membro do grupo ou não agir de forma contrária à $p$ enquanto age como um membro do grupo etc. Isto, no entanto, não requer que o indivíduo creia pessoalmente que $p$.

Parece plausível pensar que uma pequena equipe de pesquisa seja capaz de formar um comprometimento conjunto tal como descrito acima: após concluir uma pesquisa, de fato, parece ser o tipo de coisa que uma equipe de pesquisa faz quando decide publicar os resultados. A abordagem de sujeito plural, no entanto, apesar de explicar como pequenos grupos podem ser sujeitos epistêmicos, não parece ser igualmente eficaz em explicar como que grandes grupos, como a comunidade científica, seriam um sujeito epistêmico. Pois, como veremos' ${ }^{7}$, não é claro como uma coletividade composta por membros espalhados pelo globo, sem contato entre si, faria um compromisso coletivo deste tipo. A despeito disso, Gilbert acredita que a comunidade científica seja um sujeito epistêmico. Na seção seguinte apresento os argumentos de Gilbert em favor dessa tese e algumas objeções oferecidas a ela.

\section{Argumentos de Gilbert sobre a comunidade científica como sujeito epistêmico}

Gilbert (2000), apresenta uma defesa da tese de que a comunidade científica pode ser um sujeito epistêmico. Ela defende que as mudanças científicas (e.g. mudanças de paradigma em uma visão kuhniana de ciência)

\footnotetext{
6 Há conhecimento comum de que $p$ entre os membros de um grupo $\mathrm{G}$ quando (i) é o caso que $p$; (ii) todos em $G$ sabem que $p$; (iii) todos em $G$ sabem que (ii); e assim por diante (Cf. LEWIS, 1969). 7 Ver seção 4.
} 
são melhores entendidas como mudanças de crenças coletivas. Desta forma, uma mudança de paradigma em uma certa comunidade científica seria uma mudança de crença dessa comunidade. Assim, se a comunidade científica tem crenças, essas crenças poderiam ser avaliadas epistemicamente e, portanto, a comunidade científica seria um sujeito epistêmico.

A noção de mudança científica, segundo Gilbert, pressupõe a noção de consenso: a mudança científica, não é nada mais do que mudança de um consenso (GILBERT, 2000, p. 42). Por exemplo, a mudança de visão de que a Terra era o centro do universo para a visão copernicana foi uma mudança de um consenso sobre qual visão era a correta. Para Gilbert ou esta noção de consenso pode ser entendida como a mera soma das crenças individuais dos membros da comunidade científica, ou o consenso pode ser entendido como um acordo entre os membros em aceitar uma proposição como a visão da comunidade. Assim, o consenso formado pela comunidade científica pode ser explicado em termos da abordagem somatória de crenças coletivas ou segundo a abordagem não somatória de sujeito plural que vimos anteriormente. Gilbert rejeita a abordagem somatória como explicação adequada para a formação de consensos na comunidade científica e defende a abordagem de sujeito plural como a melhor opção, pois, como veremos, para Gilbert a abordagem de sujeito plural é a que melhor explica a dinâmica da mudança científica onde a abordagem somatória falharia, como ficará claro na discussão a seguir.

A comunidade científica leva tempo para mudar suas visões consolidadas. Por exemplo, Copérnico publicou sua teoria da movimentação planetária em 1543, mas levou cerca de 75 anos para a comunidade dos astrônomos europeus aceitá-la (WRAY, 2007). Gilbert defende que esse conservadorismo no pensamento científico é melhor explicado pela abordagem de sujeito plural de crenças coletivas, pois não se trata de mudar as crenças individuais, mas de mudar a visão do grupo todo (GILBERT, 2000). O pondo chave é que a abordagem de sujeito plural de crenças coletivas acomoda duas hipóteses empíricas, segundo Gilbert, associadas às mudanças científicas. A primeira é a chamada "pressão-de-pares", 
segundo a qual os membros da comunidade científica cobram, ainda que tacitamente, um comprometimento por parte dos outros membros da comunidade em manter a visão científica aceita. A segunda hipótese é a de que são os membros marginais, tais como jovens cientistas, os responsáveis pelas mudanças na visão da comunidade.

Se o consenso em comunidades científicas fosse meramente a soma das crenças individuais, o efeito de compromisso sugerido pela hipótese da pressão-de-pares ficaria sem explicação, visto que na abordagem somatória não há um compromisso entre os membros com a visão do grupo. Assim, a abordagem somatória também falha em explicar por que alguns membros de uma comunidade científica mantêm uma certa visão mesmo quando não acreditam pessoalmente nelas por pressão do compromisso imposto pela comunidade (GILBERT, 2000. p. 44). Isso faz com que, segundo Gilbert, sejam os membros mais novos ou marginais da comunidade que iniciam as mudanças científicas, pois eles estão menos comprometidos com o acordo que sustenta a visão do grupo. Esse segundo fenômeno, mais uma vez, é mais bem explicado pela abordagem de sujeito plural: indivíduos que entram muito posteriormente em um comprometimento conjunto, que sustenta uma visão coletiva, estariam menos suscetíveis à pressão imposta por este comprometimento. Mas se o requerimento para o consenso fosse apenas a soma das crenças individuais, como exige a abordagem somatória, ficaria difícil explicar tal fenômeno.

Se a argumentação de Gilbert estiver correta, então comunidades científicas têm crenças em um sentido não somatório. Tais crenças, por serem irredutíveis às crenças individuais, permitem que a comunidade seja tratada como um sujeito epistêmico. Logo, comunidades científicas podem ser sujeitos epistêmicos. Mas a conclusão de Gilbert é sustentada por duas premissas empíricas: uma acerca de que os pares pressionam os membros da comunidade para manterem suas posições quanto a visão do grupo, e outra que afirma que indivíduos marginais, como novos cientistas, são aqueles mais propensos a iniciarem uma mudança na visão da comunidade. Por serem premissas empíricas, era de se esperar 
que Gilbert fornecesse estudos e dados empíricos em sua defesa. Mas, ela não fornecesse tais dados. Gilbert menciona apenas um estudo que investiga o papel de membros de fora da comunidade na descoberta da teoria bacterial de úlceras pépticas (THAGARD, 1999). Mas isso não parece suficiente, principalmente porque há estudos que sugerem o contrário do que essas premissas empíricas, centrais no argumento de Gilbert, afirmam. Por exemplo, contra a hipótese de pressão-de-pares Stephen Cole (1992) e Mirian Solomon (2001) argumentam que nos limites da pesquisa científica o desacordo acerca de teorias é um estado de coisas comum. Conforme Kristina Rolin (2008), mesmo que os cientistas concordem em algumas questões, eles também discordam em um grande número de hipóteses e teorias. Já contra a hipótese de que jovens cientistas são os mais propensos a desafiarem o consenso científico, Wray argumenta que essa é uma ideia falsa sobre as mudanças científicas. Ele argumenta que essa ideia é fruto de uma falácia estatística que não leva em conta o fato de que, ao longo da história da ciência, o número de jovens cientistas foi desproporcionalmente maior (WRAY, 2007).

Portanto, o argumento de Gilbert falha por depender de premissas problemáticas e questionáveis as quais ela não fornecesse suporte adequado. Na última seção deste trabalho eu argumento que a comunidade científica pode ser tratada como um sujeito epistêmico, mas evito a estratégia de Gilbert de que crenças coletivas são o que melhor explicam a dinâmica da mudança científica (apesar de minha posição ser consistente com a de Gilbert). Minha defesa terá como base a ideia de que a comunidade científica é capaz de estabelecer um comprometimento que gere crenças coletivas irredutíveis a soma das crenças de seus membros. No entanto, como veremos na seção a seguir, Wray argumenta justamente na direção oposta: comunidades não são capazes de formar crenças irredutíveis e, portanto, não podem ser sujeitos epistêmicos. Desta forma, antes de apresentar uma defesa de como comunidades formam crenças irredutíveis, será preciso demonstrar que as objeções de Wray, contra a tese de que comunidades têm crenças irredutíveis, não funcionam. 


\section{Argumentos de Wray sobre equipes de pesquisa como sujeitos epistêmicos}

Wray (2007) investiga três tipos de configurações de grupos: equipes de pesquisa, comunidades de especialização (como a comunidade dos astrofísicos ou a comunidade dos arqueólogos) e a comunidade científica no seu todo, e investiga quais dos tipos seriam capazes de ter conhecimento coletivo; ou seja, quais tipos de grupos seriam sujeitos epistêmicos na terminologia que estou adotando neste trabalho. A tese de Wray neste ensaio é de que apenas equipes de pesquisa são portadoras de conhecimento coletivo e uma boa parte de sua argumentação dedica-se a objetar a ideia de que comunidades como um todo podem ter conhecimento. Seu principal alvo é a posição Margaret Gilbert (2000) que já foi analisada na seção anterior. No que se segue irei me voltar à defesa de Wray de que apenas equipes são sujeitos epistêmicos.

A tese de Wray de que apenas equipes são sujeitos epistêmicos repousa em uma distinção feita por Emile Durkheim (1997) entre dois tipos de sociedade: sociedades caracterizadas por solidariedade mecânica e sociedades caracterizadas por solidariedade orgânica. As primeiras são aquelas onde o que une os indivíduos é o fato de que estes têm pensamentos, crenças e valores similares entre si. Por outro lado, nas últimas, não são necessariamente as crenças e valores similares que mantém os indivíduos unidos, mas, a dependência funcional entre esses indivíduos: "como várias partes de um organismo, os vários membros constitutivos dependem do funcionamento adequado dos outros membros" (WRAY, 2007, p. 342). Para Durkheim, sociedades simples são caracterizadas por solidariedade mecânica e sociedades complexas são caracterizadas por solidariedade orgânica. Isto não significa, no entanto, que uma sociedade não pode exibir ambas solidariedades, ou seja, uma sociedade pode ser formada por indivíduos que partilham as mesmas crenças e valores e é organizada de maneira a dependerem do funcionamento adequado uns dos outros. A distinção didática, por assim dizer, visa mostrar que não é 
necessário, para se organizar uma sociedade, que os indivíduos tenham as mesmas crenças e valores.

Wray estende os conceitos de solidariedade mecânica e orgânica de sociedades a grupos:

Solidariedades mecânica e orgânica são propriedades de outros grupos sociais além de sociedades. Por exemplo, um grupo de estudantes em um colégio tem solidariedade mecânica, uma mentalidade que os leva ao mesmo lugar para buscar sua formação acadêmica. Em contraste, um grupo de operários tipicamente tem solidariedade orgânica. Cada trabalhador depende de todos os outros trabalhadores, sem que nenhum trabalhador possa produzir o produto final por conta própria. É apenas como um coletivo, trabalhando em conjunto, que o produto final pode ser produzido (2007, p. 342).

E então argumenta que

Para um grupo ter conhecimento coletivo ele tem de ser capaz de adotar uma visão ${ }^{8}$ que não é redutível às visões de seus membros individuais. Grupos com solidariedade orgânica têm essa capacidade, enquanto grupos com solidariedade mecânica carecem dessa capacidade (2007, p. 342).

A tese de Wray aqui exposta tem duas partes. Primeiro, Wray afirma que um grupo só é um sujeito epistêmico quando se mostra capaz de formar visões irredutíveis às crenças individuais de seus membros. $\mathrm{E}$, em segundo, ele afirma que apenas grupos com solidariedade orgânica têm essa capacidade. Eu estou de acordo com a primeira parte da tese de Wray, de fato, este ponto foi exatamente o que foi defendido na seção 1 deste trabalho. Mas a segunda afirmação já não é tão óbvia. Portanto, temos

\footnotetext{
8 Wray prefere o termo "visão" ao termo "crença" para falar de atitudes doxásticas coletivas. Isto porque Wray é um rejeicionista (WRAY, 2002), ou seja, Wray rejeita a tese de que crenças coletivas são crenças do mesmo tipo que crenças individuais (ver nota 2 neste trabalho).
} 
de olhar com maior atenção para compreender porque Wray pensa que apenas grupos com solidariedade orgânica são capazes de formar visões irredutíveis a fim de prosseguirmos com a investigação.

A ideia de que grupos com solidariedade mecânica têm visões que são redutíveis aos membros de um grupo parece seguir-se da própria caracterização da noção de solidariedade mecânica. Uma vez que grupos com solidariedade mecânica estão unidos por partilharem crenças e valores comuns, parece-se seguir-se que qualquer crença assumida pelo grupo será uma crença comum entre os membros. É isto que Wray parece sugerir quando afirma que

Por exemplo, as pessoas que moram na mesma cidade podem ter solidariedade mecânica. Porque eles tendem a ter estilos de vida semelhantes, em consequência da sua vida na mesma cidade, eles tendem a ter muitos pontos de vista em comum. Mas na medida que tal grupo compartilha uma visão, ela pode ser abordada somativamente (2007, p. 342).

Isto pode ficar mais claro com outro exemplo. Imagine uma comunidade religiosa de um determinado bairro, não é só o caso de os membros dessa comunidade partilharem o mesmo estilo de vida ou frequentarem a mesma igreja aos domingos. O que une essa comunidade é o fato deles terem as mesmas crenças religiosas. Essa comunidade é caracterizada por solidariedade mecânica. Suas visões religiosas são compartilhadas e, portanto, podem ser caracterizadas somativamente. Por outro lado, em comunidades caracterizadas por solidariedade orgânica, uma vez que essas não são unidas por crenças em comum, e sim por um tipo de dependência funcional, as visões a elas atribuídas podem ser irredutíveis às crenças de seus membros. Wray menciona o caso do Comitế que aceita uma proposição de que um certo candidato é o melhor qualificado para o

\footnotetext{
9 Ver seção 1.
} 
cargo (2007, p. 342) e afirma que em casos assim o comitê pode aceitar uma proposição que não é a opinião pessoal dos membros ${ }^{10}$.

O próximo passo de Wray é analisar quais tipos de grupo, dentre os tipos em investigação - a saber, equipes de pesquisa, comunidades de especialização ou a comunidade científica como um todo - exibem solidariedade orgânica. Primeiro, sobre equipes de pesquisa, Wray afirma que "nem todas as equipes de pesquisa são iguais. Alguns são enormes, formados por centenas de cientistas e pessoal de apoio [...]. Outras consistem em apenas alguns cientistas" (2007, p. 343), portanto é preciso considerar essas duas configurações em separado. Quanto a grandes equipes de pesquisa, podemos identificar que há uma grande diferenciação entre papéis desempenhados pelos membros segundo suas especialidades, tais equipes são formadas por pessoas que atuam em diferentes áreas de especialização: de engenheiros que cuidam da manutenção dos equipamentos a cientistas que trabalham em diferentes laboratórios. Em alguns casos, grandes equipes organizam fóruns onde debatem acerca das conclusões alcançadas nos experimentos (KNORR-CETINA, 1999). Dada a estrutura de grandes equipes de pesquisa, Wray conclui que essas exibem solidariedade orgânica e, portanto, são capazes de adotar visões que são irredutíveis a seus membros. Logo, grandes equipes de pesquisa são, na análise de Wray, sujeitos epistêmicos.

Quanto a pequenas equipes de pesquisa, Wray reconhece que sua análise sobre grandes grupos tem como base a explícita noção de divisão de trabalho encontradas em tais grupos. Em pequenos grupos de pesquisa, no entanto, essa noção de divisão de trabalho, em termos de pessoas com diferentes habilidades (como especialistas em áreas diferentes) pode não existir. Pequenas equipes de pesquisa podem ser formadas por pessoas da mesma área e, além disso, trabalharem juntos em um projeto

\footnotetext{
10 Não é claro qual é a dependência funcional que um comitê deste tipo exibe. Penso que uma boa interpretação do pensamento de Wray seria dizer que os membros do comitê dependem funcionalmente uns dos outros porque um membro não pode tomar sozinho a decisão de qual é o melhor candidato para o cargo.
} 
sem que este necessariamente precise ser desenvolvido em grupo. Assim, não é claro se, nessa abordagem de Wray, equipes pequenas exibiram solidariedade orgânica.

Isso, evidentemente, é um problema, porque casos de pequenas equipes são tratados na literatura como casos paradigmáticos de sujeitos epistêmicos coletivos. Wray parece estar ciente disso, pois afirma que "[m] esmo esses grupos, no entanto, são, em princípio, capazes de conhecer coletivamente. Se tal grupo tem conhecimento coletivo, entretanto, depende se a visão de grupo é irredutivelmente a visão de grupo" (WRAY, 2007, p. 343). Mas saber se a visão de pequenas equipes é irredutível a visão dos membros, para Wray, é uma questão empírica que tem de ser analisada caso a caso.

Tendo concluído a análise de equipes de pesquisa, Wray se volta à noção de comunidade. Primeiro ele considera comunidades de especialização, por exemplo, a comunidade dos arqueólogos ou a comunidade dos bioquímicos. Para Wray, membros de comunidades de especialização têm muito em comum: "eles pertencem a mesma organização profissional, leem os mesmos periódicos e assistem as mesmas conferências. Além disso, eles partilham muitas crenças que são acarretadas pelas teorias amplamente aceitas no seu campo" (2007, p. 344). Ou seja, Wray sugere que comunidades são caracterizadas como exibindo solidariedade mecânica. Por outro lado, não há dependência funcional entre os membros de uma comunidade de especialização, uma vez que, segundo Wray, os vários cientistas e equipes trabalhando na mesma área de conhecimento não dependem funcionalmente uns dos outros. Portanto, tais comunidades não podem ser caracterizadas como possuidoras de solidariedade orgânica e, como consequência, não podem ter visões irredutíveis o que as desqualificam como sujeitos epistêmicos na visão de Wray.

Por fim, Wray considera a comunidade científica como um todo. Podemos pensar, sugere Wray, que a comunidade científica exibe algum tipo de dependência funcional entre os diversos campos de pesquisa, onde cada subárea investiga a sua parte da realidade e contribui para o 
objetivo geral da ciência de formar uma imagem completa do mundo. Assim, a comunidade científica seria um sujeito epistêmico. No entanto, Wray argumenta que essa imagem da ciência é falsa: as várias subáreas da ciência não são um todo organizado. Wray evoca a defesa de Hacking (1992) de que não há uma linguagem comum nas ciências e, por isso, as teorias de subcampos diversos não são necessariamente consistentes. Evidentemente, os cientistas esperam que suas teorias sejam consistentes com outras, mas isso trata-se mais de um ideal regulativo. Na prática, as preocupações com consistência têm um caráter local, ou seja, em relação às teorias que tenham impacto direto com a pesquisa em questão. Desta forma, Wray conclui que "seria inadequado considerar a comunidade científica como capaz de adotar uma visão que é irredutível à visão do grupo e, portanto, é inapropriado atribuir conhecimento a comunidade como um todo" (2007, p. 344). De acordo com Wray, então, equipes de pesquisa são sujeitos epistêmicos enquanto comunidades de especialização ou a comunidade científica como um todo não. Enquanto a primeira exibe (ou pode exibir) solidariedade orgânica as últimas são caracterizadas como exibindo solidariedade mecânica e, em virtude disso, suas visões não são irredutíveis às visões dos membros da comunidade.

No próximo item eu irei argumentar, contra Wray, que a noção de solidariedade orgânica não é nem necessária nem suficiente para um grupo ter visão coletiva irredutível às visões individuais. Isso bastará para demonstrar que Wray não consegue sustentar com base na noção de solidariedade orgânica que comunidades não são sujeitos epistêmicos.

\subsection{Objeções à posição de Wray}

A posição de Wray discutida anteriormente pode ser reconstruída no seguinte argumento:

P1: Para que uma coletividade seja um sujeito epistêmico ela tem de ser capaz de formar visões coletivas que são irredutíveis às visões (crenças e opiniões) individuais dos membros que a compõe; 
P2: para ser capaz de formar visões coletivas que são irredutíveis às visões (crenças e opiniões) individuais de seus membros uma coletividade tem de ser unida por solidariedade orgânica;

P3: a comunidade científica não é unida por solidariedade orgânica;

C: logo, a comunidade científica não é um sujeito epistêmico.

Na seção 1 deste trabalho eu apresentei a ideia expressa em $\mathrm{P}_{1}$ como a base para sustentar que grupos podem ser sujeitos epistêmicos. Como vimos, aquilo que faz de um grupo um sujeito epistêmico é a capacidade de formar visões coletivas que são irredutíveis às crenças e opiniões pessoais de seus membros. Desta forma, eu estou comprometido com a ideia expressa em $\mathrm{P}_{1}$ e, portanto, minhas objeções a Wray terão de recair sobre $\mathrm{P}_{2}$ ou $\mathrm{P}_{3}$. Apesar de $\mathrm{P}_{3}$ ser questionável ${ }^{11}$ eu não quero me comprometer com a ideia de que a comunidade científica exibe divisão de trabalho cognitivo orientada a um objetivo comum, por isso minhas objeções serão contra P2. Contra P2, irei argumentar que exibir solidariedade orgânica não é nem necessário e nem suficiente para que um grupo forme uma visão irredutível a que seus membros possuem.

Como talvez esteja claro para o leitor a essa altura, tudo que um grupo precisa para formar uma visão coletiva irredutível é ser capaz de estabelecer um comprometimento conjunto nos moldes da abordagem de sujeito plural explicada na seção 1. Ao contrário do que pensa Wray, não acredito que seja preciso que os membros de um grupo tenham de ser dependentes funcionalmente uns dos outros para realizarem esse tipo de comprometimento. Por outro lado, mesmo que um grupo seja unido por solidariedade orgânica, isto não garante que este grupo tenha uma visão coletiva. Vejamos dois exemplos que ajudam a ilustrar objeções.

Primeiro, quanto a suficiência da solidariedade orgânica para visões coletivas irredutíveis, considere o caso de trabalhadores de uma fábrica

\footnotetext{
1 Por exemplo, Bird (2014) defende que a comunidade científica é unida por uma divisão de trabalho que visa o progresso do conhecimento científico e, portanto, é unida por solidariedade orgânica.
} 
de móveis. Claramente este grupo é unido por solidariedade orgânica: cada trabalhador manufatura uma parte do móvel a ser construído e depende um do outro para construir um móvel completo. Suponha que alguns trabalhadores dessa fábrica acreditem que seus salários estão baixos e que uma greve é a melhor solução para este problema. Mas esses trabalhadores têm medo de perderem o emprego e, portanto, não se manifestam a respeito dessa crença. Não se pode dizer, nesse caso, que o grupo acredita que a greve é a melhor solução para resolver o problema do baixo salário'2. O fato deste grupo ser unido por solidariedade orgânica não garante que tenham visões coletivas irredutíveis' ${ }^{13}$. Wray parece reconhecer isso quando afirma:

Vale ressaltar que não é a mera dependência que torna o grupo capaz de conhecimento coletivo. Nem é o fato de que o grupo é intencionalmente organizado para explorar os recursos que só são possíveis graças aos esforços conjuntos do grupo que o torna capaz de conhecimento coletivo. De fato, essas são condições necessárias para o conhecimento coletivo. Mas, o que faz com que tal grupo seja capaz de conhecimento é que o grupo tem a capacidade de adotar uma visão que é irredutivelmente a visão do grupo (WRAY, 2007, p. 343. Grifo do autor).

Portanto, a mera dependência funcional do grupo não é suficiente para a formação de uma atitude doxástica coletiva irredutível. Wray não explica o que seria preciso acrescentar para que tal atitude se estabelecesse. Mas podemos pensar plausivelmente que, para adotar uma visão que é "irredutivelmente a visão do grupo", os trabalhadores precisam se

\footnotetext{
12 Este contraexemplo é baseado no contra exemplo de crenças privadas utilizado por Gilbert (1987) contra a visão somatória de crenças coletivas.

13 Pode-se questionar se a dependência funcional para construir móveis é relevante para avaliar a crença coletiva acerca da greve. No entanto, é importante ressaltar que este grupo em particular é também dependente funcionalmente para decidir sobre a greve, uma vez que um trabalhador sozinho não pode decidir isso.
} 
reunir, discutir sobre o assunto e, então, decidirem que a greve é a melhor solução ao problema do baixo salário. Ou seja, precisam expressar publicamente sua decisão quanto a greve. Nota-se que esses são elementos do comprometimento conjunto da abordagem de Gilbert. Elementos tais que, a meu entender, desempenham papel essencial na formação da atitude coletiva. No entanto, apesar de não ser suficiente, como vimos, Wray considera que a dependência funcional é necessária para um grupo formar visões irredutíveis. O próximo exemplo, contudo, coloca em causa a ideia de que a dependência funcional, ou seja, a solidariedade orgânica seja condição necessária para um grupo formar visões irredutíveis.

Para avaliar se a solidariedade orgânica é uma condição necessária para visões coletivas irredutíveis, vamos retomar exemplo da comunidade religiosa. Como vimos, na visão de Wray, uma comunidade religiosa seria unida por solidariedade mecânica. Uma comunidade desse tipo é unida pelo fato de partilharem as mesmas crenças religiosas. Mas não se segue disso que uma comunidade deste tipo não possa formar uma visão coletiva irredutível. Isto porque, mesmo que seja unida por um conjunto de crenças em comum em determinado domínio (e.g. o domínio das crenças religiosas), um grupo pode ter divergência entre a visão do grupo e a soma das crenças individuais dos membros do grupo em uma crença no mesmo domínio. Por exemplo, uma certa denominação pentecostal no Brasil considerava que era um pecado assistir televisão. Em determinado momento, no entanto, tal posição foi abandonada. Apesar disso, muitos membros mais conservadores mantiveram a crença pessoal de que era pecado assistir televisão. Podemos supor plausivelmente que em um momento inicial (logo após a mudança de posicionamento da igreja) a maioria dos membros acreditava pessoalmente que era pecado assistir televisão. Mas a despeito da crença pessoal da maioria dos membros, a crença da igreja pentecostal é a de que não é pecado assistir televisão a partir do momento que o líder (ou líderes) da igreja assumiu (assumiram) isso. Assim, há um caso de divergência entre a atitude coletiva e a crença da maioria dos membros, o que indica a irredutibilidade da visão coletiva 
adotada. A carência de solidariedade orgânica, portanto, não parece impedir que grupos tenham uma visão irredutível. ${ }^{14}$

Se os exemplos acima funcionaram, a premissa $\mathrm{P} 2$ do argumento de Wray é falsa. Portanto, Wray não consegue demonstrar que comunidades não podem ser sujeitos epistêmicos. O caminho para defender que comunidades científicas podem ser sujeitos epistêmicos, portanto, está aberto. Mas, apenas mostrar que o argumento de Wray não funciona, não é suficiente. Defender que comunidades científicas podem ser capazes de instanciar atitudes doxásticas exigirá mais alguns passos. Considere a seguinte premissa:

P2*: para ser capaz de formar visões coletivas que são irredutíveis às visões (crenças e opiniões) individuais de seus membros uma coletividade tem de ser capaz de estabelecer um comprometimento conjunto.

A argumentação na introdução deste trabalho e as considerações que fiz contra a posição de Wray nessa seção fornecem um bom suporte para $\mathrm{P}_{2}$ *. Assim, o que é preciso para defender que comunidades podem ser sujeitos epistêmicos é defender o seguinte:

P3*: A comunidade científica pode estabelecer um comprometimento conjunto.

Em conjunto com $\mathrm{P}_{1}$ (do argumento reconstruído de Wray), $\mathrm{P}_{2} *$ e $\mathrm{P}_{3}$ * levam à conclusão de que comunidades podem ser sujeitos epistêmicos. $\mathrm{P}_{3}$, no entanto, precisa de suporte. Não está claro como uma coletividade formada por inúmeras pessoas de diversas especializações e espalhadas pelo globo, como a comunidade científica, formaria um comprometimento

\footnotetext{
14 Neste exemplo ainda não está claro o que tornou a visão irredutível possível, mas o que explica a visão coletiva neste caso é o comprometimento conjunto que os membros da igreja têm com proposições assumidas por seus líderes religiosos. Esse tipo de comprometimento, estabelecido por um sistema de autoridade existente no grupo, no entanto, ainda não foi devidamente explicado neste ponto da discussão e será trabalhado adiante na seção 4 .
} 
conjunto. Além disso, Alexander Bird (2014) argumenta que P3* é falsa. Portanto, antes de oferecer uma defesa da $\mathrm{P}_{3}$, eu analiso a proposta de Bird na próxima seção.

\section{Defesa da comunidade científica como sujeito epistêmico coletivo}

Nesta seção, ofereço uma defesa de $\mathrm{P}_{3}{ }^{*}$, ou seja, a premissa que afirma que a comunidade científica é capaz de estabelecer um comprometimento conjunto. Antes, no entanto, é necessário considerarmos as objeções de Bird (2014) contra a $\mathrm{P}_{3}$ *. Bird primeiro apresenta o que seria necessário para que um grupo forme um comprometimento conjunto:

Um grupo G acredita que p somente no caso de os membros de $\mathrm{G}$ aceitarem conjuntamente que $p$. Isso ocorre apenas quando cada membro expressou publicamente vontade para que $p$ se apresente como o ponto de vista de G; ou cada membro expressou publicamente um comprometimento conjunto para aceitar que $p$, condicional a uma expressão pública de comprometimento por parte dos outros membros de G. (BIRD, 2014, p. 44).

A exigência de expressar "publicamente vontade para que $p$ se apresente como o ponto de vista de G", segundo Bird, não pode ser cumprida, ou, pelo menos, não é factualmente cumprida por indivíduos engajados na comunidade científica: "os participantes na ciência ampla claramente não pensam em si mesmos como um grupo onde cada membro expressou sua vontade para que $p$ se apresente como a visão do grupo" (BIRD, 2006, p. 48). Além disso, esta exigência tem, na concepção de Bird, a implicação de que os membros de um grupo desejariam estar cientes das práticas e métodos que levam à conclusão tomada como a visão do grupo:

Se, de fato, é requerido o comprometimento público para com a conclusão, então nós esperaríamos que os indivíduos, 
a fim de estarem confortáveis com tal comprometimento, irão querer saber como a conclusão foi alcançada e estarem aptos a influenciar essa conclusão (BIRD, 2014, p. 44).

Mais uma vez, não parece possível que os membros da comunidade científica cumpram tal exigência. Portanto, considerando que um requisito para os membros de um grupo estabelecerem um comprometimento conjunto é condição de estarem conscientes acerca dos métodos e procedimentos do grupo, podemos sumarizar as objeções de Bird da seguinte maneira: (1 - Os membros da comunidade científica não podem estar cientes de todos os métodos e procedimentos que levam a uma conclusão de que $p$ proposta como visão do grupo; ( 2 - então, os membros da comunidade científica não podem se expressar publicamente em concordância com uma proposição $p$ tomada como a visão do grupo; (3 - logo, a comunidade científica não pode formar um comprometimento conjunto. ${ }^{15}$

Tentarei responder a objeção de Bird argumentando contra (1)-(2). Começando por (2), a exigência de que os membros de um grupo expressem publicamente sua concordância com a visão do grupo é, de fato, um problema para o modelo de comprometimento. Mas apenas para a abordagem de sujeito plural de Margareth Gilbert. Uma outra abordagem não somatória que faz uso da noção de comprometimento conjunto, chamada "abordagem posicional", defendida por Raimo Tuomela $(1992,1995)$, não tem uma exigência tão forte ${ }^{16}$. Na abordagem posicional, Tuomela faz uma distinção

\footnotetext{
15 Apesar de concluir que a comunidade científica não é capaz de formar um comprometimento conjunto, Bird defende que a comunidade científica pode ser tratada como um sujeito epistêmico. O fato de a comunidade não ser capaz de um comprometimento conjunto, para Bird, é um problema para a tese de que o comprometimento conjunto é o que explica sujeitos epistêmicos coletivos. Como a comunidade científica é um sujeito epistêmico e não é capaz de realizar um compromisso conjunto, o modelo de comprometimento não é um modelo adequado. Bird então argumenta em favor de outro modelo, a saber, o modelo de cognição distribuída. Por questões de limitações de espaço, contudo, tal modelo não foi abordado neste trabalho.

16 A abordagem de Tuomela, no entanto, difere de Gilbert em um aspecto importante. Diferente de Gilbert, Tuomela defende que as atitudes doxásticas formadas por grupos são aceitações coletivas e não crenças coletivas. No entanto, conforme explicado na nota 1, neste trabalho eu me mantenho neutro sobre se atitudes doxásticas coletivas são crenças ou aceitações.
} 
entre membros operativos e não operativos de um grupo. Membros operativos são aqueles membros responsáveis pela crença coletiva ter o conteúdo que tem. Ou seja, são aqueles que decidem aceitar se $p$ como a visão do grupo. Por exemplo, no caso de uma corporação, os diretores podem ser os membros operativos no que tange às decisões gerais da corporação, onde aqueles que, digamos, trabalham no departamento pessoal são membros não operativos para estes assuntos. O grande diferencial da abordagem de Tuomela é que a aceitação dos membros não operativos de uma visão adotada pelos membros operativos não precisa ser uma aceitação explícita: os membros não operativos aceitam tacitamente as visões adotadas pelos membros operativos enquanto executam suas funções como membros do grupo. Além disso, não precisamos nem supor que a aceitação tácita é uma aceitação factual, pois podemos entender que a aceitação é normativa, no sentido de que os membros não operativos de um grupo $\mathrm{G}$ devem posicionalmente ${ }^{17}$ aceitar que $p$, em virtude dos membros operativos de $\mathrm{G}$ aceitaram coletivamente que $p$. Os membros não operativos têm o dever de aceitar a visão do grupo por força do sistema de autoridade sob o qual o grupo opera. Isso fica claro quando consideramos instituições, corporações, governos etc. Nesses tipos de grupo, quando os membros operativos determinam uma proposição como a visão do grupo, os membros não operativos têm o dever de agir como se acreditassem nessa proposição enquanto agem como membros do grupo, e isso não requer que os membros expressem publicamente sua concordância com a visão assumida. Portanto, nessa abordagem, não é preciso que todos os membros de um grupo se expressem publicamente com relação a visão coletiva.

No entanto, pode não ser claro como isso acontece na comunidade científica, já que, em princípio, a comunidade científica não tem uma estrutura hierárquica explícita como uma corporação tem. Mas pode-se argumentar (NIINILUOTO, 2003) que a ciência exibe um sistema de

17 Por "aceitar posicionalmente" entende-se que enquanto atua como membro do grupo o indivíduo deve agir como se acreditasse na proposição coletivamente aceita pelo grupo. 
autoridade implícito, onde especialistas em uma área de conhecimento são autoridades para as proposições que caem sob essa área. Ou seja, os especialistas podem ser tratados como membros operativos para proposições em sua área de especialidade. Por exemplo, se infectologistas, após concluírem suas pesquisas, aceitam coletivamente que o vírus da zika pode provocar microcefalia em bebês, caso seja contraído durante a gestação, outros membros não operativos (para proposições da área de infectologia) da comunidade médica, digamos, obstetras, devem aceitar posicionalmente essa proposição. Tal aceitação não exige que os obstetras expressem sua vontade em concordância com a visão coletiva. Portanto, se não precisamos supor que todos os membros de um grupo precisam expressar publicamente sua vontade em aceitar uma proposição como a visão do grupo, não temos razões para aceitar (2) do argumento de Bird.

Duas objeções precisam ser consideradas quanto ao ponto acima. ${ }^{18}$ Primeiro, pode-se argumentar que casos de desacordo entre especialistas podem minar o sistema de autoridade na ciência ou tornar difícil reconhecer quem são os especialistas. Essa objeção perde força se considerarmos que casos de desacordo sequer são casos de visões coletivamente aceitas. Visões coletivamente aceitas por um grupo de especialidade são aquelas onde não há mais desacordos entre seus membros. Só há uma crença coletiva de que $p$, na abordagem posicional, se os membros operativos coletivamente aceitam que $p$. Se há desacordo entre os membros operativos, não há crença coletiva. O meu ponto, contudo, é o de que (contra a premissa 2 do argumento de Bird) em alguns casos é possível que se forme um consenso na comunidade científica sobre uma proposição ou conjunto de proposições sem que todos os membros da comunidade se expressem publicamente em concordância isso. Penso que o exemplo anterior ilustra tal caso.

18 Agradeço aos pareceristas da Veritas por este ponto. 
Uma segunda objeção seria a de que os membros não operativos para uma questão sobre se $p$ apenas aceitam o testemunho dos membros operativos e isso não os tornam (os membros operativos e os não operativos) um sujeito coletivo. Penso que essa objeção não funciona porque meramente aceitar um testemunho de que $p$ não gera um compromisso por parte daquele que aceita o testemunho do mesmo modo que o compromisso gerado em um comprometimento conjunto. Alguém pode rejeitar a recomendação de um médico para tomar uma vacina porque, contrariando o consenso médico, acredita que vacinas não são seguras. Mas um profissional de saúde enquanto atua como um profissional da saúde é constrangido pela força do consenso a agir como se acreditasse que vacinas são seguras independente de crer ou não pessoalmente nisso.

A premissa (1) é a mais parte mais fraca do argumento de Bird. Se, por um lado, é plausível pensar que na comunidade científica não é possível que todos os membros estejam cientes de como, ou quais métodos, foram utilizados para se alcançar a conclusão quanto a visão do grupo; por outro lado, não é claro porque isso seria uma exigência da noção de comprometimento conjunto. Mesmo no sentido forte de comprometimento da abordagem de sujeito plural, onde os membros têm de expressar publicamente sua vontade de aceitar a visão do grupo, não se segue que os membros tenham que estar cientes de como a proposição, coletivamente aceita, foi alcançada. Como vimos, Bird menciona como razão para sustentar essa consequência que, em virtude dos requerimentos do modelo de comprometimento, "seria de esperar que os indivíduos, a fim de estarem confortáveis com um tal compromisso, iriam querer saber como a conclusão foi alcançada e serem capazes de influenciar essa conclusão" (BIRD, 2014, p. 44). Mas isso é meramente uma interpretação psicológica da situação e não uma implicação lógica do comprometimento conjunto. Portanto, como (1) não se segue logicamente do modelo de compromisso, Bird não consegue demonstrar que o requerimento deste modelo implica em (1). 
Contudo, outra objeção, seria dizer que, embora não seja necessário que todos os membros de um grupo tenham ciência dos métodos e procedimentos que levaram a uma conclusão que deve ser aceita como visão do grupo, se comprometer com uma proposição sem conhecimento de como ela foi alcançada, apenas com base na autoridade de alguém, prejudicaria o caráter epistêmico da visão coletiva. Afinal, os membros de um grupo aceitariam e manteriam uma visão não por razões epistêmicas, mas em virtude de algum sistema de autoridade ao qual devem obedecer. Talvez seja por isso que Bird pensa que os membros iriam querer serem "capazes de influenciar [a] conclusão" (BIRD, 2014, p. 44).

Portanto, mesmo que os membros de um grupo estabeleçam um comprometimento conjunto de aceitar $p$ como a visão do grupo (sem expressarem publicamente sua vontade de aceitar $p$ e sem saberem como $p$ foi alcançada) apenas em virtude de se submeterem à autoridade dos membros operativos do grupo, tal grupo não seria considerado um sujeito coletivo epistêmico (talvez ainda possa ser considerado um sujeito coletivo prático). Essa objeção, contudo, parece sugerir que é epistemicamente inapropriado aceitar uma visão com base na autoridade de outros. Mas essa objeção tem força apenas se pressupormos uma concepção puramente individualista de epistemologia. A chamada "epistemologia do testemunho" fornece argumentos convincentes para rejeitarmos tal pressuposição individualista (SCHMITT, 1999) ${ }^{19}$. Uma vez, portanto, que o individualismo epistêmico é uma tese questionável, não temos razões para aceitar uma objeção que a pressupõe.

\section{Considerações finais}

Neste trabalho argumentei que um grupo pode ser um sujeito epistêmico se for capaz de ter crenças coletivas irredutíveis à soma

\footnotetext{
19 A epistemologia do testemunho oferece teorias que explicam como alguém pode aceitar justificadamente que $p$ com base na palavra/autoridade de outros. Uma explicação detalhada, no entanto, fugiria ao escopo deste trabalho.
} 
das crenças individuais de seus membros. Essas crenças coletivas são formadas em virtude de um comprometimento conjunto. Contra Wray e Bird argumentei que a comunidade científica é capaz de formar visões irredutíveis em virtude de um comprometimento conjunto realizado pelos membros da comunidade. Esse comprometimento por sua vez, deriva do sistema implícito de autoridade que a ciência pode exibir, onde especialistas determinam as visões do grupo e não especialistas (quanto ao conteúdo da visão em questão) aceitam tácita e normativamente as visões coletivas. A argumentação aqui exposta, se correta, suporta a tese de que a comunidade científica pode ser um sujeito epistêmico coletivo.

\section{Referências}

BIRD, A. When Is There a Group that Knows? In: LACKEY, J. (org.). Essays in Collective Epistemology. Oxford: Oxford University Press, 2014. p. 42-63. https://doi.org/10.1093/acprof:0so/9780199665792.003.0003

COLE, S. Making Science: Between Nature and Society. Cambridge: Harvard University Press, 1992.

DURKHEIM, E.; COSER, A. The Division of Labor in Society. Reprint edition ed. New York: Free Press, 1997.

GILBERT, M. Modelling Collective Belief. Synthese, [s. l.], v. 73, n. 1, p. 185-204, 1987. https://doi.org/10.1007/BFo0485446

GILBERT, M. On Social Facts. Princeton: Princeton University Press, 1989.

GILBERT, M. Sociality and Responsibility: New Essays in Plural Subject Theory. Lanham: Rowman \& Littlefield Publishers, 2000.

GILBERT, M. Collective Epistemology. Episteme, [s. l.], v. 1, n. 2, p. 95-107, 2004. https://doi.org/10.3366/epi.2004.1.2.95

GILBERT, M. Collective Action. In: O'CONNOR, T.; SANDIS, C. (ed.). A Companion to Philosophy of Action. Malden: Wiley-Blackwel, 2011, p. 67. https://doi.org/10.1002/9781444323528.chg

HACKING, I. The disunified sciences. In: ELVEE, R. Q. The end of science: Attack and defense. Lanham: University Press of America, 1992. 
KNORR-CETINA, K. Epistemic Cultures: How the Sciences Make Knowledge. Cambridge: Harvard University Press, 1999.

LEWIS, David. Convention: A Philosophical Study. Cambridge: Harvard University Press, 1969.

MATHIESEN, K. Can Groups Be Epistemic Agents? In: SCHMID, H. B.; SIRTES, D.; WEBER, M. (org.). Collective Epistemology. Frankfurt: Ontos Verlag, 2011. p. 20-23.

NIINILUOTO, I. Science as Collective Knowledge. In: SINTONEN, M.; YLIKOSKI, P.; MILLER, K. (org.). Realism in Action. [S. l.]: Springer Netherlands, 2003, p. 269-278. https://doi.org/10.1007/978-94-007-1046-7 18

MOREIRA, D.. Grupos podem ter conhecimento? Fundamento: revista de filosofia, [s. l.], v. 1, p. 51-75, 2016.

MULLER, F. M. Conhecimento Coletivo em Perspectiva. In: BAVARESCO, A.; GROSS, M. V. Villanova; RODRIGUES, T. V. (org.). Projetos de Filosofia II. Porto Alegre: EDIPUCRS, 2012, v. 1, p. 68-91.

ROLIN, K. Science as collective knowledge. Cognitive Systems Research. Perspectives on Social Cognition, [s. l.], v. 9, n. 1-2, p. 115-124, 2008. https:// doi.org/10.1016/j.cogsys.2007.07.007

SCHMITT, F. Social Epistemology. In: GRECO, J.; SOSA, E. (ed.). The Blackwell Guide to Epistemology. Malden: Blackwell, 1999, p. 354-382. https://doi.org/ 10.1111/b.9780631202912.1998.00018.x

SCHMITT, F. Socializing Metaphysics: An Introduction. In: SCHMITT, F. (ed.). Socializing Metaphysics: The Nature of Social Reality. Lanham: MD Rowman/ Littlefield, 2003.

SOLOMON, M.. Social Empiricism. Cambridge: A Bradford Book, 2001.

THAGARD, P.. How Scientists Explain Disease. Princenton: Princeton University Press, 1999.

TUOMELA, R.. Group Beliefs. Synthese, [s. l.], v. 91, n. 3, p. 285-318, 1992.

TUOMELA, R.. The Importance of US: A Philosophical Study of Basic Social Notions. Stanford: Stanford University Press, 1995. https://doi. org/10.1086/233857

TUOMELA, R.. Group Knowledge Analyzed. Episteme, [s. l.], v. 1, n. 2, p. 109127, 2004. 
WRAY, K. Brad. Who has Scientific Knowledge? Social Epistemology, [s. l.], v. 21, n. 3, p. 337-347, 2007. https://doi.org/10.1080/02691720701674288

\section{Endereço Postal}

Universidade Federal do Maranhão - DEFIL/CCH

Av. dos Portugueses, 1966.

Bairro: Bacanga.

CEP 65080-805. São Luís - MA 